\title{
Communal Space Design of High-Rise Apartments: A Literature Review
}

\author{
Wenyuan $\mathrm{Wu}$, Xin Janet Ge* \\ Faculty of Design, Architecture and Building, University of Technology Sydney \\ *xinjanet.ge@uts.edu.au
}

Received: $30^{\text {th }}$ March 2020

Final version received: $28^{\text {th }}$ April 2020

Satisfactory communal space in high-rise apartments helps to create a harmonious living atmosphere and enhance neighbourhood relations. This review summarises and analyses the research on the design of communal areas in high-rise apartments with consideration of five aspects: space division, universal design, security design, landscape design and decoration design. The aim is to achieve a comprehensive understanding of current design concepts relating to communal space in high-rise apartments and to identify key design considerations that are necessary for the development of sustainable high-rise apartments. The paper proceeds with three objectives: (1) to develop a comprehensive policy for communal space to support the sustainable development of high-rise apartments; (2) to identify research on the building materials that can be used to improve the environment of the communal spaces; and, (3) to identify areas that can improve the planning and management of open spaces in high-rise apartments with the help of existing information technology. Overall, this review provides some useful insights for the sustainable development of high-rise apartments in terms of shared-space design, while revealing gaps in the literature and areas for further research.

Keywords: High-rise apartments, Communal space, Design, Sustainable development

\section{INTRODUCTION}

Ongoing urbanisation has been a major factor in rapid population growth. Many high-rise apartments were built to simultaneously address the scarcity of land and accommodate increasing housing needs (Reddy 1996; Je \& Lee 2010; Holdsworth, Kenny, Cooke \& Matfin 2019). High-rise apartments are usually located in premium neighbourhoods and provide amenities such as gyms, sharing rooms, etc., at a relatively affordable price. However, some researchers claim that high-rise apartments lead to a series of social problems including the deterioration in the mental health of the residents (Fanning 1967; Richman 1974), a reduced sense of belonging (Hall 1966; Husaini, Moore \& Castor 1991; Cho \& Lee 2011), deficient supporting facilities (Deng 2012), and a lack of monitoring that leads to an increased crime rate (Costello 2005; Gifford 2007; Li 2007).

Communal spaces in high-rise apartments are places for residents to interact and communicate. Such spaces comprise two main components: the open area and passageway inside the apartment block, such as the lobby, corridor, public underground parking, elevator, stairs, gym, and other shared areas; and the associated areas outside the apartment block, including the 'public domain interface', semiopen and open courtyards or gardens, and rooftop (NSW Department of Planning and Environment 2015).

High-quality communal spaces are the basis for creating healthy neighbourhood relationships. They help to maintain a sense of belonging and cohesion for residents, and can help to improve social problems that may exist within high-rise apartments (Chang 2015). However, imprudent building planning and/or space design can result in reduced or unused joint spaces (Mahdavinejad, Mashayekhi \& Ghaedi 2012). Therefore, flexible communal space design is necessary for providing a positive living environment (Tian 2001).

This type of design was embedded in the typical traditional housing which considers the 
elements of local topography, climate, and social conditions, that meet basic human needs and conform to the laws of nature (Li 2004; Deng 2012). However, most modern high-rise buildings have met the high-density urbanisation but neglected the traditional design elements (Astuti, Setijanti \& Soemarno 2017; Matovnikov, Matovnikova \& Samoylenko 2018). By this measure, both modern and traditional housing have their merits and drawbacks. Therefore, it is particularly important to understand both traditional and contemporary design preferences and apply these ideas to the design of communal space to address the above-mentioned problems that exist with high-rise apartments (Franck \& Mostoller 1995).

Through a comprehensive understanding of the scholarly design philosophy of communal space in the high-rise apartment, this review seeks to identify any research gaps and develop a research direction for the future. The review will summarise and analyse the research on communal space in consideration of five aspects: space division, universal design, security design, landscape design and decoration design. Three design elements beneficial to the sustainable development of communal space in the future will be proposed.

\section{RESEARCH METHOD}

This study applies the meta-analysis method in the systematic review to conduct a quantitative analysis of the literature relating to the design of communal space in high-rise apartments. The reasons for this approach are twofold. First, the purpose of the systematic literature review is consistent with the original intention of this review, that is, to comprehensively and accurately identify the progress of the research by integrating the literature in specific research fields (Mulrow 1987; Green, Johnson \& Adams 2006). Second, a meta-analysis in the systematic literature review is a standardised review method with normalised research steps (Moher, Liberati, Tetzlaff \& Altman 2009; Hart 2018). These steps are intended to establish a structured search strategy and identify the inclusion and exclusion criteria (Paré, Trudel, Jaana \& Kitsiou 2015), to search for research-related literature from multiple sources and databases, and to conduct a quantitative analysis of search results (Hart, 2018). In summary, three steps of literature retrieval - selection, coding and analysis were adopted to understand the research of scholars.

\subsection{Literature search}

Based on the academic databases and publications available at the University library, this review involved an extensive literature search through Google Scholar, ProQuest, Scopus, and CNKI (China National Knowledge Infrastructure database). These are considered the four most acceptable full-text databases available for a comprehensive search of disciplines. The reason for choosing CNKI is that valid literature retrieved from Google searches pointed to the CNKI database. Also, the authors understand Chinese, whereas the other three databases are all operated in English.

For the review, the title/abstract/keyword field was selected in the databases to systematically and extensively search articles related to communal areas using keywords and free text words. The search string contained synonyms for three core words: 'high-rise apartments', 'communal spaces' and 'design'. Several free text words, namely: 'landscape', 'environmental behaviour', 'psychology', 'old people' and 'children' were also used. Lastly, 187 articles related to the design of communal space were retrieved.

\subsection{Literature selection}

All literature needed to be further refined and filtered before its selection for analysis. The selection criteria of this review were as follows. (1) Publications were only retained from journals, conference papers, and theses, and a few reports and book chapters. (2) Articles that could not be retrieved by full-text were excluded. Unfortunately, many of the articles were only available by purchase, and the reviewer did not have the budget to pay for papers. (3) There was no cut-off date set for literature retrieval, with the most recent search being December 2019.

After screening, 106 articles were selected from Google Scholar and 81 articles were retrieved from the other three databases. After excluding 36 articles that were retrieved more than once, and 24 irrelevant articles, a total of 127 papers remained. Following this, 6 articles in languages other than English and Chinese and 32 articles with abstracts only were also excluded. The 89 full-text papers retained for analysis include journal articles $(\mathrm{n}=52)$, theses $(n=23)$, conference papers $(n=11)$, and book chapters $(n=3)$. The main retrieval steps above are illustrated in Figure 1 and all references were imported into EndNote X9. 


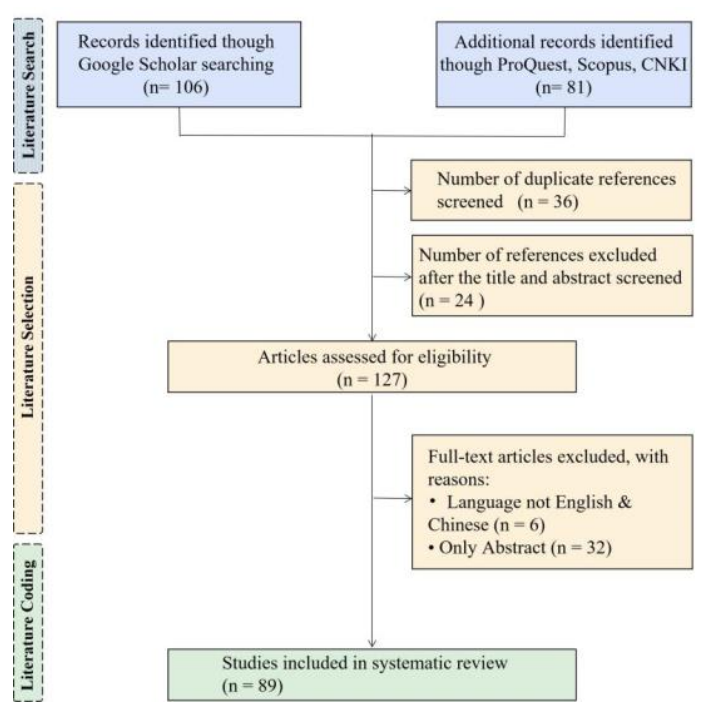

Figure 1: Steps of literature retrieval

\subsection{Literature coding}

The main task of the literature coding was to extract the research-related data from the identified literature, and to classify and encode the data. The main methods of coding were by title, subtitle, keywords, abstract, research method and conclusion. The coding content consisted of: a) article title; b) researcher/s name/s; c) publication name; d) publication year; e) research field of article; and f) major design elements or ideas mentioned in each study.

\section{RESULTS}

Table 1 shows the research focus of the identified articles to be centred mainly around four research fields: design, psychology and behaviour, sociology and landscape science.

(Source: Author)

Table 1: Classification of the Identified literature

\begin{tabular}{|l|l|c|c|}
\hline Topics & Focused on & $\begin{array}{c}\text { Paper } \\
\text { No. }\end{array}$ & Percentage \\
\hline Design & $\begin{array}{l}\text { space design, environmental design, and architectural } \\
\text { design }\end{array}$ & 39 & $44 \%$ \\
\hline $\begin{array}{l}\text { Psychology \& } \\
\text { Behaviour }\end{array}$ & $\begin{array}{l}\text { the relationships between human psychology, } \\
\text { behaviour and the environment }\end{array}$ & 13 & $15 \%$ \\
\hline Sociology & $\begin{array}{l}\text { neighbourhood social contact, housing safety, and } \\
\text { residents' satisfaction }\end{array}$ & 28 & $31 \%$ \\
\hline Landscape & sciencepublic space landscape and vegetation & 9 & $10 \%$ \\
\hline & & 89 & $100 \%$ \\
\hline
\end{tabular}

\subsection{Factors in designing communal space}

The design of communal space is an interdisciplinary field. Many determinants need to be considered comprehensively in the planning programme and are emphasised differently from various perspectives. Using a questionnaire survey of 1500 respondents, Malek, Mohammad and Nashar (2018) found that social sustainability, use pattern, place attachment, facilities, safety and security, nature preferences, and activities and accessibility were the main determinants to achieve the quality of open spaces in Malaysia. In the current review, the main factors to be considered are summarised as the following:

(1) The architectural form of high-rise apartments

As an indispensable part of the high-rise apartment, the design of communal space depends on the structure of the building. The main types of architectural features mentioned in the existing research include underground space (Zhao 2007), bottom space (Zhang \& Sui 2006; Wei 2015), patio (Chan 2005), courtyard (Wang 2008; Matovnikov et al. 2018), rooftop (Lum 2011), lobby (Noguchi \& Tsukidate 2002), elevator lobby (Bee \& Im 2016), and highplatform type space (Shen \& He 2005). The different methods of space design correspond to different building structures (Lin 2018).

(2) Residents' living needs and habits in age groups

The age span of residents in high-rise apartments dictates that the communal space should be inclusive. Residents' demands for shared areas should consider individual living needs (Engür 2013). Some scholars have applied Maslow's hierarchy of needs (Xiong 2000; Itma 2018), which requires that sheltered and comfortable living spaces meet the basic physiological and safety needs of humans (Sajad, R. A. \& Sajad, S. A. 2016). After these basic needs are satisfied, people pay more attention to 
the spiritual satisfaction of housing, that is, they need to feel a sense of belonging and respect in the living environment, which is known as selfactualisation needs. Residents of different age groups have certain needs in terms of physiology and psychology. Children (Coley, William, Sullivan \& Kuo. 1997; Sharghi, Maulan, Salleh \& Salim 2014) and the elderly (Temelová \& Slezáková 2014; Tang 2015) have higher requirements for a better quality of shared spaces. Therefore, for these age groups, safety and usability are the two major design factors to be considered (Zhang 2007; Zhang \& Wang 2012). Furthermore, while young people and office workers prefer outdoor or public entertainment areas, they also seek to relieve the pressures of work through high-quality communal spaces in their apartment blocks, although they maintain a low demand for the communal space (Baharuddin 2017). It is evident that a comprehensive understanding of different users' personality traits and living habits in residential buildings (Astuti et al. 2017; Feng 2016), especially traditional living habits (Wang 2008), can provide a valuable reference for the spatial layouts, which can be made more suitable for the behavioural needs of residents (Lee, Li, Chen \& Liu 2005; Engür 2013).

\section{(3) Human psychology and behaviour}

A consideration of human psychology and behaviour is essential when designing communal spaces. A reasonable space layout is not only conducive to more functional areas, but also to the benefit of neighbourhood communication (Zhao 2007; McMurtrie 2012). The psychologist Derk de Jonge proposed the boundary effect, in which people tend to socialise at the edges and corners of open spaces to gain a sense of domain (Han 2007). Similarly, the anthropologist Hall (1966) suggested that 1.2 to 3.6 metres is the most socially appropriate distance for humans. Gehl (2011) believed that communal spaces should be designed according to our daily activities. According to the theory of neighbourhood typology, the sociologists Perry, Blumenfeld and Bardet agreed that the size of a neighbourhood group should be considered to be no more than 12 households for the establishment of healthy interpersonal relationships (Li 1999). These verified scientific conclusions are based on the human psychology and behaviour mode, and have a guiding function in the design of communal areas.

\section{(4) Surrounding environment}

It is clearly stated in the NSW Apartment Design Guide (ADG) (NSW Department of Planning and Environment 2015) that the design of communal space should cater to the development of surrounding communities and/or the urban environment. This is because the surrounding environment can help to integrate the housing development into the broader urban and community landscape (Franck \& Mostoller 1995; Tribhuwaneswari, Darjosanjoto \& Rachmawati 2016). Thus, consideration of the natural environment, such as greening, climate, and other factors, is indispensable (Chan 2005; Chang 2015).

\section{(5) Culture and religion}

Cultural and religious factors in the design of communal space can enhance the residents' sense of belonging on the spiritual level (Zhang $\&$ Wang 2012). This is especially so in countries and regions that receive large numbers of immigrants, where the heterogeneity of language and culture seem to have a meaningful impact on the harmony of the neighbourhood (Forrest, La Grange \& Ngai-Ming 2002). Integrating culture and religion into the physical spatial characteristics of the built environment can improve neighbourhood interaction between different cultural backgrounds (Abbaszadeh, Ibrahim, Baharuddin \& Salim 2009). Changes in culture can affect the relationships between residents within social space (Abbaszadeh et al. 2009; Itma 2018) and lifestyle (Hadi \& Bin 2013). In a mono-cultural country, traditional culture should be embedded into the design of communal space to maintain people's traditional life and good relations within the neighbourhood (Abbaszadeh et al. 2009; Itma 2018). It can also reduce the negative impact of modern housing on residents' traditional lives (Itma 2018). Modern elements are more suitable to highlight the cultural atmosphere of communal space in multicultural countries, because of their universality.

\subsection{Research approach}

Different approaches have been adopted by researchers based on various disciplinary standpoints. From the perspective of design, some scholars followed the three main steps of the literature review, field research and case study. In particular, architectural simulation (Wang \& Bay 2008), pattern design (Park, Kim $\&$ Lee 2007) and other digital model design 
methods were developed. Cho and Lee (2011) verified the feasibility of the conceptual model of communal space through living projects. From the perspective of sociology, most researchers focused on investigation and evaluation, setting up multiple variables, and pointing out the shortcomings of the architectural projects to improve the communal area (Kim 2003; Lee 2007; Sharghi et al. 2014). From the perspective of psychology and behavioural studies, scholars have evaluated human actions in an existing shared area by testing the residents' actual behaviours (Tanaka, Yamada, Nakamura, Ishii \& Watanabe 2013), and established a dynamic model (McMurtrie 2012) to explain the influence of space on human interaction and psychology. From the perspective of landscape science, some scholars used Computational Fluid Dynamics to study the correlation between micro-climate factors of communal space and the open-space layout of residential areas (Yin 2013).

\section{DISCUSSION}

This discussion focuses mainly on the characteristics of traditional residential shared areas and sustainable development strategy in communal space design with consideration of five aspects: space division, universal design, security design, landscape design and decoration design.

Through summarising the relevant literature, the patterns characteristic of communal spaces in traditional housing design were understood in the following ways. First, communal space is directly connected with the street and has a high degree of conformity with the surrounding environment of the city (Abbaszadeh et al. 2009). Second, communal areas connect public and private space, and play a transitional role. Multiple path nodes create space with hierarchical characteristics (Wang 2008). In Eastern and Western countries, the layout of the communal areas in traditional housing is different. In Western countries, the communal space lies between two semi-open private courtyards and is usually used as a driveway (Turkington, Van Kempen \& Wassenberg 2004; Fong \& Paul 2011). In Eastern countries, the communal space is a courtyard shared by several families, which may include a semi-open mini porch (Li 2007; Deng 2012). In the latter instance, the communal space connects a broader range of public and private domains, and the continuous multi-level spatial network gradually strengthens the formation of the spatial domain (Deng 2012; Chang 2015). The authors have illustrated the layout schematic diagram of traditional residence in Eastern and Western country, as shown in Figure 2.

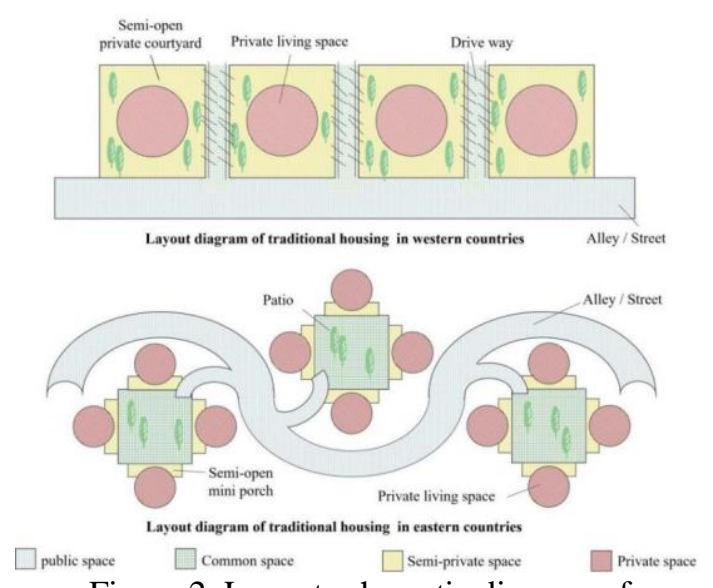

Figure 2: Layout schematic diagram of traditional residence in Eastern and Western country (Source: Author)

Third, traditional communal space is multifunctional. Due to the small indoor areas of traditional houses, the use of shared areas has expanded to integrate daily life, and entertainment and neighbourhood social activities, among other things (Li 2016). Lastly, there is a diverse implantation of natural elements. Due to the grounding characteristics of traditional housing, the communal spaces have a higher native vegetation coverage rate (Wu 2014). Given the communal space characteristics of traditional housing, scholars have posited several design strategies as follow.

Five characteristics of communal space design were identified as presented below:

\subsection{Space division}

(1) Setting up shared platforms in adjacent floors of high-rise apartments to form 'terrestrial space' (Qu \& Yang 2009; Engür 2013).

The idea behind this design is to divide the large population into smaller neighbourhoods for purposes of proximity (Xiong 2000; Chua 1995). In high-rise buildings, proximity is one of the main determinants in promoting neighbourhood interaction (Bochner, Duncan, Kennedy \& Orr 1976). However, residents may unconsciously avoid the social interaction between neighbours 
in high-density living environments (Li 2003). Multi-level sharing platforms, such as the sky gardens or the sky streets, can form natural places for daily communication between residents (Tian 2001).

(2) Establishing the communal space pattern with service at its core and improving its identifiability.

Weiner (1984) believed that the division of communal space should take service as the core element and set up communication floors that can accommodate various conveniences. It is conducive to residents' public gatherings and interactions at different levels. Bay (2004) evaluated the surveys of Bedok Court in eastern Singapore and showed that the semi-open space with the front courtyard as a serviced area could actively encourage a more natural lifestyle. Huang and Wang (2004) proposed a layout of communal spaces akin to cell structures; that is, a core site providing services or activities for residents is determined according to the building structure and residential circle. This layout of communal spaces can be divided into central and eccentric areas from the building, but mostly located at the first level structure. Lee (2011) pointed out that the main lobbies and channel hubs should be planned as the core spaces, such as a social hub or a leisure activity area because chance encounters between residents may lead to social interaction.

(3) The accessibility and orientation of the path should be made clear and used to form a spatial context with a cohesive force (Li 2004; Wu 2014).

Gestalt psychology mentions that the establishment of an environment cannot be separated from three elements: centre, path and field ( $\mathrm{Li}$ 1999). The home is the centre of every inhabitant's mind, and the path is the way to reach the centre $(\mathrm{Li}, 2004)$, and the shared area (field) is the node in the path. Huang (2006) used behavioural observation methods to investigate the impact of courtyard design on social interaction over the course of 21 days in three high-rise residential projects. The results show that the number of resident interactions in path and node far more than any other design elements in the courtyard. In communal space, residents can find a psychological path with a sense of security and belonging through the relative positioning of space. $\mathrm{Li} \mathrm{(2004)}$ proposed that setting shared spaces on different private levels of the residents' home paths achieved order and hierarchy in vision and psychology. Sharghi et al. (2014) suggested that the path setting should be based on the preference of residents' daily behaviours. Park et al. (2007) and Engür (2013) pointed out that connecting the horizontal passages and vertical lines of communal space to tree-like structures can reinforce people's inner sense of home.

(4) Effectively using the redundant space in apartment blocks to build a shared space that conforms to the building pattern forms and hierarchical relationship of the space.

The design idea is to set up the communal space coinciding with the edge effect (Tian 2001; Lin 2018) and social distance in the valid path of residents returning home (Zhang \& Lawson 2009; Li \& Feng 2011; Chang 2015): examples include the elevator lobby (Huang 2012), stair corner (Kim 2014), or some small extension platform (Foth \& Sanders 2005). These redundant spaces can supplement the deficiency of social spaces in the apartment (Chua 1995; $\mathrm{Li}$ 2003). Bee and Im (2016) proposed the planning concept of "less is more". They used the elevator lobby on each floor as a shared space to create a sense of belonging. Jin (2017) suggested that the transitional area of the existing residence should be regenerated in a low-cost way. The closed scale of a shared area increases the opportunities for social interaction between neighbours and avoids wasted communal spaces (Huang \& Wang 2004; Li 2007; Han 2007; Chen 2007).

Overall, the design of an available multi-level communal space allows residents to feel an orientation similar to traditional housing ( $\mathrm{Li}$ 2016; Adiyanti, Nareswari \& Suryandono 2018). Spatial stratification is not only a mechanism to control land use but also a potential link with social networks that foster neighbourhood communication and provide security (Drucker \& Gumpert 1991; Li 2003). The authors have illustrated the above views by the diagram presented in Figure 3. 


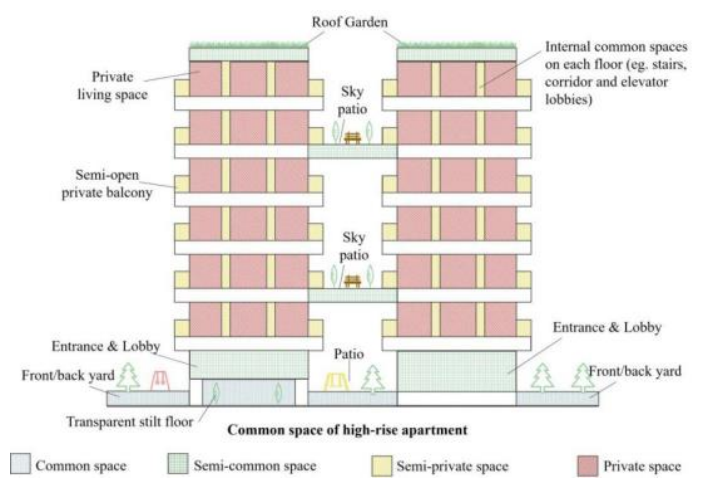

Figure 3: Schematic diagram of communal space of high-rise apartments (Source: Author)

\subsection{Universal design}

Universal design is the most basic design principle in urban public space, with the purpose of providing fair access to all users (Choa, Hab, Lima \& Chongb 2018). The universal design of communal space mainly considers the right for all to use shared space and facilities. The shared space should fully consider the residents' age and the frequency and length of time of their activities to reasonably arrange the function of the space (Kim 2003; Wu, Tao \& Ni 2004; Astuti et al. 2017). For example, children and the elderly always use the communal space in the morning and afternoon, while young people prefer morning or evening. Children and older people tend to socialise in groups, while young people's social space is full of isolated or quiet space (Holland, Clark, Katz \& Peace 2007). Therefore, the satisfaction of spatial rights for different age groups can be distinguished from the spatial hierarchy and time but is not absolute (Feng 2016; Yu 2018). For the use of public facilities, the universal design should consider the physiological needs of different groups and consider them from a usability standpoint (Tang 2015; Yu 2018), for example, by installing handrails in corridors or stairs, and ramps at the entrance. Natural environment characteristics of communal spaces are influential social variables that affect residents' emotions and behaviours (Molana 2016). It is critical to provide safe, convenient and liveable environments for the elderly, children, and the disabled (Rahravi Poodeh \& Pouriaye Vali 2014; Choa et al. 2018).

\subsection{Security design}

Security is a crucial factor for consideration in the design of communal space. In terms of designing the general layout of communal spaces, Xiong (2000) proposed to separate the traffic intersection from residential units and establish an effective evacuation safety channel to avoid the impact of fire on vertical movement. In terms of local area design, it is necessary to avoid blind corners or weak visual lines of sight to reduce the possibility of hiding criminals. Additional lighting and monitoring facilities in the shadows are also important safeguards (Yuen 2004). Coley et al. (1997) and Prihatmanti and Taib (2018) argued that natural factors such as trees and flowers could increase opportunities for residents to interact socially. Informal interactions increased the sense of familiarity and responsibility between residents and strengthened the monitoring of outdoor areas (Abbaszadeh et al. 2009; Bee \& Im 2016; Aziz, Ahmad \& Nordin 2017). Also, maintaining the interrelationship and independence between shared and private spaces is crucial for the protection of privacy (Swapan, Marinova \& Bay 2018). Sarkissian, Bateman, Hurley and Young (2013) and Andrews, Warner and Robson (2018) believed that children's play areas in communal space should be large enough to be located away from private areas because children are not cognisant of privacy when they are playing.

\subsection{Landscape design}

Scholars have considered the strategies for the landscape design of communal space from two viewpoints. On the one hand, scholars believed that landscape design can partially improve the natural climate of the apartment area, especially in cold areas (Noguchi \& Tsukidate 2002; Yin 2013) and also tropical regions (Bay 2004; Jamaludin, Hussein \& Tahir 2018). Leng and Yuan (2012) and Feng (2016) pointed out that the planting of the natural landscape could improve the light and wind environment of communal spaces and result in more people staying for longer. Some scholars recommended the strategy of implementing multi-storey planting and greening into the shared space. Matovnikov et al. (2018) argued that multi-layer plants alter the microclimate and the radiation connected to the building, and that planning features that mimic nature can improve the ecological performance of high-rise residential areas. Prihatmanti \& Taib (2018) proposed that the addition of green rooves and vertical greening systems in high-rise apartments 
effectively reduce the heat island effect. This design approach has ecological and aesthetic benefits and solves the problem of food security in urban environments. It also has the potential for broad application in limited greening spaces and improves the thermal comfort of high-rise buildings. Chan (2005) proposed that landscape design should integrate hanging gardens into the surrounding environment. Fong and Paul (2011) suggested that planting activities could encourage residents to participate in the management of shared gardens and socialise with others. Shen and He (2005) used computeraided design in the design and simulation of the physical conditions of the site, which helped to make the communal space environment more natural.

\subsection{Decoration design}

In communal space, the decorative effect of integrating diversity can enhance residents' sense of identity and belonging (Lum 2011). Li (2004) set up some special space treatment effects in the elevator lobby, entrance lobby, and other areas, such as decorating the ceiling with modern lighting points and lines, to enhance perceptions of the space. Ghanbari (2018) added some cultural and religious design elements in the shared space to meet the demands of residents for a traditional feel. Yu, Sui, Bai and Jiao (2018) suggested that the decoration effect of shared areas should be visual and novel, and the colour collocation could distinguish different leisure function and used population. Smith (2012) advised that changes in materials, lighting, sound and ceiling height could be used in the decoration process to create a high-quality visual and audible communal space.

\section{RESEARCH GAP}

\subsection{Research on the relevant policies of communal spaces}

High-quality communal space cannot be separated from the support of governmental policies (Glaeser \& Sacerdote 2000; Chan 2005; Wang 2018). Many scholars mentioned how the planning and development of shared areas in high-rise apartments lacked policies for guidance. In terms of spatial planning and quality, Matovnikov et al. (2018) indicated that the general planning stage of high-rise apartments should be formed under an orderly policy orientation. Bakaeva (2018) argued that the quality of communal spaces should be improved through building policies, and that the ratio of shared to private space under the optimal comfort level needed to be clarified. In terms of building standards, Andrews et al. (2018) pointed out that there are no clear child-friendly policies in the building guidelines of several Australian states, especially in communal areas, which is unfair to the development of children in high-rise apartments. From the perspective of economic benefits, housing policy also affects the planning of communal space. Bin Abdul Razak and Alias (2015) studied the main determinants in the development of landscape architecture in Malaysia and found that policymakers could benefit from better understanding the relationships between landscape, architecture and property development. There are disputes among various stakeholders on the actual area of shared spaces, since the housing price, in China, for example, is measured by the unit of square metres. Tang (2017) proposed that in the construction of residential communal space, national legislation should provide explicit support, such as the conversion method of shared areas, space management, definitions of communal space property rights and obligations of various stakeholders. Clear policy orientation is the legal guarantee of market operation. Levin, Arthurson and Zierschalso (2014) summarised the reasons for the failure of Melbourne's 'Carlton redevelopment project (stage 1)', pointing out that the different views and economic interests of the tenants, government officials, private developers and private residents on the redevelopment project harmed the implementation of the priority design principle. Li (2007) argued that government departments should give developers and designers some encouragement and support in policies, and only in this way can the virtuous circle of high-rise housing development be promoted. As can be seen, the political and economic decisions made by the government and the planning philosophy of some housing stakeholders, such as the estate developers, determine the communal space planning of high-rise apartments (Zhu 2015). In terms of management, Sun (2007) and Vasilevska (2013) proposed that local authorities, shared and private sectors, investors, planners and residents are all partners in decision-making negotiation. Policy-makers and those engaged in building standards need to have a deeper understanding of residents' actual needs or involve residents in relevant seminars (Vasilevska 2013). Thus, policy research related to the communal space of high-rise apartments is necessary. 


\subsection{Research on the building materials used for communal spaces}

The green building materials used in communal areas help to create a healthy living environment for residents. At present, few scholars have studied the choice of building materials for communal space. But this subject is crucial to the sustainability of high-rise apartments. In general, materials used in communal space tend to be consistent with building materials. The choice of materials should pose no harm to people's health and safety, and natural materials are encouraged for use because they can save resources and minimise the project's impact on the environment (Larasati, Duijvestein \& Fraaij 2007). Additionally, the cost of materials is also a factor to consider when choosing. Again, the aesthetic functions of the materials chosen need to be considered, using the concise design layout and overall aesthetic effect as the criterion (Bagheri \& Shahroodi 2015). Kennedy and Buys (2015) suggested the need to study the properties and characteristics of the materials used in both the private and communal spaces of apartment blocks and to make a more active contribution to the liveable and sustainable high-density community. They also suggested, along with Georgi and Sarikou (2005), that in the landscape design of high-rise apartments, natural materials that are environmentally sustainable, economical, easy to maintain and of high aesthetic quality, should be selected.

\subsection{Research on information technology and communal space}

The shared environment of apartments in the social network is characterised by fast-paced technological changes and the social behaviour of residents (Brignull, Izadi, Fitzpatrick, Rogers $\&$ Rodden 2004). The planning and policymaking for shared spaces in high-rise apartments require interdisciplinary communication among the fields of sociology, computer science, architecture and space design (Foth \& Sanders 2005). Electronic communication media has changed people's demand for their living environment and has caused some residents to gradually break from face-to-face human interaction (Brignull et al. 2004). But every coin has two sides. The sustainable development of the communal space can make use of the current digital media or information networks. Drucker and Gumpert (1991) advised that the integration of the planning and management of high-rise apartments with the use and development of media has helped to reshape the interaction between residents, for instance, chat group or discussion board. Foth and Sanders (2005) pointed out that the planning of communal space can use modern technology to enhance the privacy, exclusivity, permeability and flexibility of the area in terms of scale, form and functional value. As contemporary public interaction is influenced by the development of media (Lee et al. 2005), how to use existing technologies to promote the sustainable development of communal space is a problem worthy of further research.

\section{CONCLUSION}

The communal space of high-rise apartments is the area between private and urban public spaces (Smith 2012). Scholars paid attention to the aggregation method of internal and external shared areas of buildings (Huang 2006), the function of communal space (Choa et al. 2018) and the hierarchical division from unit buildings to shared space (Engür 2013). This review has studied the design strategy of communal space, and summarised and analysed the relevant research made by scholars on sustainable development of these spaces. Based on the comprehensive research results, it can be seen that scholars believe that the design of communal space can return to the form of traditional residential shared areas, and can improve on it in combination with current social developments and architectural structure (Malik \& Hassan 2019). The main design strategies can be summarised as follows: (1) multiple platform spaces are used in combination with the architectural structure to form a small neighbourhood social circles (Han 2007); (2) with the service space as the core, multiple semicommunal or semi-private spaces are designed on the effective path of residents to form hierarchical spatial divisions, so that residents can have a sense of belonging and security (Lee 2011; Swapan et al. 2018); (3) the space division and public facilities of high-rise apartments should be people-oriented and integrated into the basic concept of general design, taking into account the needs of residents of different age groups (Astuti et al. 2017); (4) security should be considered as an essential design element in the planning of communal space (Xiong 2000); (5) shared areas should include multi-layer plants according to local natural climate, or reasonably arranged landscape space, such as establishing an aerial platform, roof garden, etc., (Matovnikov et 
al. 2018; Ghazali \& Davis 2014); and, (6) simplicity and innovation in the decoration design of communal spaces should be sought to meet aesthetic requirements (Lum 2011).

Simultaneously, three research gaps have been identified: (1) it is necessary to focus on the development of communal space from the perspective of policy to weigh various interests and provide comprehensive policy support for sustainable development (Bin Abdul Razak \& Alias 2015); (2) it is also necessary to increase research on building materials to improve the design of shared spaces (Kennedy \& Buys 2015); and, (3) further study is needed to improve the planning and management of communal areas with the help of existing information technology (Foth \& Sanders 2005). In conclusion, sustainable development of communal space can be established through understanding and analysing from the perspective of humanoriented requirements, identifying residents' needs for the surrounding environment, absorbing the essence of traditional architecture, and incorporating these into the design process.

\section{ACKNOWLEDGEMENT}

This research is supported by an Australian Government Research Training Program Scholarship, which offset the training fee during PhD's study.

\section{REFERENCES}

Abbaszadeh, S., Ibrahim, R., Baharuddin, M. N., \& Salim, A. (2009). Identifying Persian traditional socio-cultural behaviors for application in the design of modern highrise residences. International Journal of Architectural Research: ArchNet-IJAR, 3(3), 116-132.

Adiyanti, A. S., Nareswari, A., \& Suryandono, A. R. (2018). The Change of Space Use of Shared Space from Landed to High-Rise Settlement. The international Conference on Architectural Education in Asia (eduARCHsia 2017)

Andrews, F., Warner, E., \& Robson, B. (2018). High-rise parenting: experiences of families in private, high-rise housing in inner city Melbourne and implications for children's health. Cities \& health, 3(12), 158-168.

Astuti, S. B., Setijanti, P., \& Soemarno, I. (2017). Personalization of space in private and public setting within vertical housing as sustainable living. Journal of Architecture and Built Environment, 44(1), 37-44.

Aziz, A. A., Ahmad, A. S., \& Nordin, T. E. (2017). Flats Outdoor space as a vital social place. Asian Journal of Environment-Behaviour Studies, 2(5), 3951.

Bagheri, M., \& Shahroodi, A. (2015). Assessment and intervention of emotional preferences of users in a communal space. Journal of Contemporary Psychology, 9, 63-76.

Baharuddin, Z. B. (2017). Transitional space design in high rise residential for commuter worker in Johor Bahbu. (Master), Universiti Teknologi Malaysia.

Bakaeva, T. (2018). Collective space of high-rise housing complex. The international Conference on Architectural Education in Asia (eduARCHsia 2017)

Bay, J. H. (2004). Sustainable community and environment in tropical Singapore high-rise housing: the case of Bedok Court condominium. Architectural Research Quarterly, 8(3-4), 333-343.

Bee, A. S., \& Im, L. P. (2016). The provision of vertical social pockets for better social interaction in high-rise living Journal of the Malaysian Institute of Planners, 14(4), 163180.

Bin Abdul Razak, A. N., \& Alias, A. (2015). Landscape architecture as an entity of property development in Wilayah Persekutuan, Putrajaya. Journal of Design and Built Environment, 15(2). 39-47.

Brignull, H., Izadi, S., Fitzpatrick, G., Rogers, Y., \& Rodden, T., (2004). The introduction of a shared interactive surface into a communal space. In Proceedings of the 2004 ACM conference on Computer supported cooperative work. 49-58.

Bochner, S., Duncan, R., Kennedy, E., \& Orr, F. (1976). Acquaintance links between residents of a high rise building: An application of the "small world" method. The Journal of Social Psychology, 100(2), 277-284.

Chan, S.T. (2005). Communal Sky Gardens for High-Rise Residential Buildings. Paper presented at The 2005 World Sustainable Building Conference, Tokyo.

Chang, J. (2015). Research on Public Space Design of High-rise Apartment. (Master), Anhui Architecture University, CNKI. 
Chen, X. (2007). The Analysis of High-rise Housing neighbours' communication space composing Fujian Architecture \& Construction, 110(8), 21-23.

Cho, S. H., \& Lee, T. K. (2011). A study on building sustainable communities in highrise and high-density apartments-Focused on living program. Building and Environment, 46(7), 1428-1435.

Choa, M., Hab, T. M., Lima, Z. M. T., \& Chongb, K. H. (2018). "Small places" of ageing in a high-rise housing neighbourhood. Journal of Aging Studies, 47, 57-65.

Chua, B. H. (1995). A practicable concept of community in high-rise, high density housing environment. Singapore Architect, 189, 95.

Coley, R. L., William C. Sullivan, \& Kuo., F. E. (1997). Where does community grow? The social context created by nature in urban public housing. Environment and Behavior, 29(4), 468-494.

Costello, L. (2005). From prisons to penthouses: the changing images of high-rise living in Melbourne. Housing Studies, 20(1), 49-62.

Deng, W. (2012). Study on the interior public space for promoting neighborhood communication of high-rise residential buildings. (Master), Huazhong University of Science and Technology, CNKI.

Drucker, S. J., \& Gumpert, G. G. (1991). Public space and communication: The zoning of public interaction. Communication Theory, 1(4), 294-310.

Engür, Ö. (2013). Spaces of communication in high-rise residential buildings. (Master), Middle East Technical University.

Fanning, D. M. (1967). Families in flats. British Medical Journal, 4(5576), 382-386.

Feng, R. (2016). High-rise \& high-density housing in Beijing CBD area - Research on external public communication space (Master), CAFA(Central Academy of Fine Arts), CNKI.

Fong, K., \& Paul, G. (2011). The importance of nature in people's lives and how it can contribute to community in Melbourne apartments. Retrieved from Swinburne University.

Forrest, R., La Grange, A., \& Ngai-Ming, Y. (2002). Neighbourhood in a high rise, high density city: some observations on contemporary Hong Kong. The Sociological Review, 50(2), 215-240.
Foth, M., \& Sanders, P. (2005). Social networks in inner-city apartment complexes and the implications for the residential architecture of public space. Paper presented at the Augmented Public Space, the 2nd International Conference on Communities and Technologies, Milan, Italy.

Franck, K. A., \& Mostoller, M. (1995). From courts to open space to streets: changes in the site design of US public housing. Journal of Architectural and Planning Research, 12(3), 186-220.

Gehl, J. (2011). Life between buildings: using public space: Island Press.

Georgi, N. J., \& Sarikou, S. (2005). The use of nature friendly materials in urban public space. World Scientific and Engineering Academy and Society, 1(2), 180-186.

Ghanbari, J. (2018). Psychological role of architecture in social integration of immigrants in multicultural cities: Design experience of a residential mixed-function high-rise. Journal of International Migration and Integration, 20(1-16), 577592

Ghazali, M., Bajunid, A., \& Davis, P. (2014). The 'Sky neighborhood' layout. International Journal on Tall Buildings and Urban Habitat-CTBUH Journal, II, 40-47.

Gifford, R. (2007). The consequences of living in high-rise buildings. Architectural science review, 50(1), 2-17.

Glaeser, E. L., \& Sacerdote, B. (2000). The social consequences of housing. Journal of Housing Economics, 9(1-2), 1-23.

Green B. N., Johnson C. D., Adams A. (2006). Writing narrative literature reviews for peer-reviewed journals: secrets of the trade. Journal of Chiropractic Medicine. 5(3), 101-117.

Hadi, A., \& Bin, N. (2013). Vertical urban design: social and public places in the sky: the Pinnacle Duxton case study Singapore. (Doctor), University of Nottingham.

Hall, E. T. (1966). The hidden dimension: Garden City, NY: Doubleday.

Han, X. (2007). Analysis of "Boundary effect" among the neighborhood space in high-rise residence - In the modern sprit of humanities. Huazhong Architecture, 3(28), 78-80.

Hart, C. (2018). Doing a literature review: Releasing the research imagination. Sage.

Holdsworth, S., Kenny, D., Cooke, J., \& Matfin, S. (2019). Are we living with our heads in the clouds? Perceptions of liveability in the 
Melbourne high-Rise apartment market. In P. Rajagopalan, T. Moore, \& M. M. Andamon (Eds.), Energy Performance in the Australian Built Environment (pp. 181198): Springer.

Holland, C., Clark, A., Katz, J., \& Peace, S. (2007). Social interactions in urban public places: Policy Press.

Huang, J. (2012). Southern high-rise residential floor public space of comfort case study. (Master), South China University of Technology, CNKI.

Huang, S. C. L. (2006). A study of outdoor interactional spaces in high-rise housing. Landscape and Urban Planning, 78(3), 193204.

Husaini, B. A., Moore, S. T., \& Castor, R. S. (1991). Social and psychological wellbeing of Black elderly living in high-rises for the elderly. Journal of Gerontological Social Work, 16(3-4), 57-78.

Itma, M. (2018). High-Rise apartment buildings in Palestinian, in response to human needs. Journal of Engineering and Architecture, 6(1), 60-66.

Jamaludin, A. A., Hussein, H., \& Tahir, K. M. (2018). Satisfaction of residents towards internal courtyard buildings. Journal of Design and Built Environment, 18(2), 6169.

Je, H., \& Lee, J. (2010). A study on the impact of high-rise living on the health of residents. Journal of Asian Architecture and Building Engineering, 9(2), 331-338.

Jin, X. (2017). Study on the renovation strategy of the public space of existing house in Dalian. (Master), Dalian University of Technology, CNKI.

Kennedy, R. J., \& Buys, L. (2015). The impact of private and shared open space on liveability in subtropical apartment buildings. In Global Interchanges: Resurgence of the Skyscraper City, the CTBUT 2015 International Conference, United States of America, 318-323.

Kim, B. (2014). Hi-Low: new semi public space in the high-rise. (Bachelor), Hongik University.

Kim, W. P. (2003). Effects of perceived safe environment on social interaction among neighbors in the public outdoor space of high-rise apartment housing. Architectural Research, 5(1), 21-28.

Larasati, D., Duijvestein, C. A. J., \& Fraaij, A. (2007). Sustainable housing in Indonesia.
Netherlands: Delft University of Technology, 775-784.

Lee, C. K., Li, C. J., Chen, T. A., \& Liu, D. C. (2005). Exploration of key factors that influence indicators for sub-tropical sustainable buildings from an experiment of open-space apartment building. The 2005 World Sustainable Building Conference, Tokyo.

Lee, J. (2011). Quality of life and semipublic spaces in high-rise mixed-use housing complexes in South Korea. Journal of Asian Architecture and Building Engineering, 10(1), 149-156.

Lee, K. (2007). Sustainability assessment and development direction of super high-rise residential complexes from the viewpoints of residents. Journal of Asian Architecture and Building Engineering, 6(1), 127-134.

Leng, H., \& Yuan, Q. (2012). Planning and design strategies of open spaces at the bottom of high rise buildings based on environment comfort in winter cities. Advanced Materials Research. 450-451, 1041-1044.

Levin, I., Arthurson, K., \& Ziersch, A. (2014). Social mix and the role of design: Competing interests in the Carlton Public Housing Estate Redevelopment, Melbourne. Cities, 40, 23-31.

Li, L. (2004). Communality space construction of aggregation inhabitation and high-rise housing inner public space. Huazhong Architecture, 22(5), 76-79.

Li, M. (2007). Study on the inner public space of high-rise residence. (Master), Xi'an University of Architecture and Technology, CNKI.

Li, P. (2003). The neighbor contact space in the internal transportation system in high-rise residence Housing Materials \& Applications, 31(1), 8-10.

Li, Q., \& Feng, S. (2011). Analysis on social dimension of the neighbourhood space in high-rise residential district. Journal of Anhui Institute of Architecture \& Industry, 19(5), 34-35.

Li, Y. (2016). The study of interior public space of southern high-rise residence to promote neighborhood communication (Master), Huaqiao University, CNKI

Li, Z. (1999). Introduction to environmental behavior. Beijing: Tsinghua University Press. 
Lin, F. (2018). Unit type plane and public traffic space joint design. Fujian Architecture \& Construction, 243(9), 17-23.

Lum, S. W. M. (2011). Re-designing the apartment-high-rise through a child's perspective. (Doctor), University of Hawai'i at Mänoa.

Mahdavinejad, M., Mashayekhi, M., \& Ghaedi, A. (2012). Designing communal spaces in residential complexes. Procedia-Social and Behavioral Sciences, 51, 333-339.

Malek, N. A., Mohammad, S. Z., \& Nashar, A. (2018). Determinant factor for quality green open space assessment in Malaysia. Journal of Design and Built Environment, 18(2), 26-36.

Malik, S., \& Hassan, K. A. K. (2019). An investigation of house designs in Lahore: transformation of residential architecture from traditional to modern. Journal of Design and Built Environment, 19(1), 4959.

Matovnikov, S., Matovnikova, N., \& Samoylenko, P. (2018) (September 4-8, 2017). The problems of designing a multifunctional courtyard space of highrise buildings by the example of residential development in Volgograd. High-Rise Construction 2017 (HRC 2017), Russia.

Mcmurtrie, R. J. (2012). Feeling space dynamically: variable interpersonal meanings in high-rise apartment complexes. Visual Communication, 11(4), 511-534.

Moher, D., Liberati, A., Tetzlaff, J., \& Altman, D. G. (2009). Preferred reporting items for systematic reviews and meta-analyses: the PRISMA statement. Annals of internal medicine, 151(4), 264-269.

Molana, H. H. (2016, June 15). Evaluating sense of community in the public spaces of residential neighborhoods in Tehran, Iran. The 10th International Conference of the European Association for Architectural Education (EAAE) and the Architectural Research Centers Consortium (ARCC), Lisbon, Portugal.

Mulrow C. D. (1987). The medical review article: state of the science. Annals of Internal Medicine, 106(3), 485-488.

Noguchi, T., \& Tsukidate, T. (2002). Form, use and clearing of snow from the Gangi in winter-Study on the communal space design of public apartment houses in heavy snowfall areas in Japan. Journal of Asian
Architecture and Building Engineering, 1(1), 245-251.

NSW Department of Planning and Environment. (2015). Apartment design guide: Tools for improving the design of residential apartment development. https://www.planning.nsw.gov.au/Policyand-Legislation/Housing/ApartmentDesign-Guide

Paré G., Trudel M. C., Jaana M., Kitsiou S. (2015). Synthesizing information systems knowledge: A typology of literature reviews. Information \& Management. 52(2), 183-199.

Park, J. E., Kim, S. Y., \& Lee, H. W. (2007, June, 27-29). A study on the design of indoor communal space in the multiple dwelling housing. The Proceedings of the International Conference on Sustainable Building Asia, Seoul, Korea.

Prihatmanti, R., \& Taib, N. (2018, September 26-27). Multi-layer planting as a strategy of greening the transitional space in high-rise buildings: A review. The IOP Conference Series: Earth and Environmental Science. Banda Aceh, Indonesia.

Qu, Y., \& Yang, Z. (2009). "Terrestrial space" in high-rise residential buildings. Urbanism and Architecture, 1, 16-18.

Rahravi Poodeh, S., \& Pouriaye Vali, A. H. (2014). Investigating the characteristics of open spaces to enhance social interactions in neighborhood environments. European Online Journal of Natural and Social Sciences: Proceedings, 3(4), 148-158.

Reddy, K. N. (1996). Urban redevelopment: a study of high-rise buildings: Concept Publishing Company.

Richman, N. (1974). The effects of housing on pre-school children and their mothers. Developmental Medicine \& Child Neurology, 16(1), 53-58.

Sajad, R. A., \& Sajad, S. A. (2016). Responding human needs in Iranian traditional houses in psychological approach - case study: Haghighi House, Isfahan, Iran). Journal of Design and Built Environment. Special Issue: The 5th International Conference on Sustainable Development and Urban Conservation, 22-30.

Sarkissian, W., Bateman, R., Hurley, B., \& Young, A. (2013). Open space in mediumdensity housing guidelines for planning and design. Retrieved from Nimbin NSW.

Sharghi, A., Maulan, S. B., Salleh, I. B., \& Salim, A. S. B. S. (2014). The relationship of 
children connectivity and physical activities with satisfaction of open spaces in high rise apartments in Tehran. International Journal of Kinesiology and Sports Science, 2(3), 9-17.

Shen, H., \& He, C. (2005). Research on the public space environment design of urban residential complex of "high platform type. Architectural Journal, 4, 32-33.

Smith, M. (2012). Interactive dwelling: public space, private space and the space inbetween. (Master), The University of Detroit Mercy School of Architecture.

Sun, Y. (2007). On the design of public space and environment of multistory unit house. Science \& Technology Information, 17, 329.

Swapan, A., Marinova, D., \& Bay, J. (2018). Understanding the importance of front yard accessibility for community building: A case study of Subiaco, Western Australia. Urban Science, 2(2), 41-63.

Tanaka, M., Yamada, H., Nakamura, T., Ishii, A. \& Watanabe, Y. (2013). FatigueRecovering Effect of a House Designed With Open Space. The Journal of Science and Healing, 9(2), 82-86.

Tang, J. (2015). The necessity of optimal described the design of public space in residential construction. Fujian

Architecture \& Construction, 207(9), 4346.

Tang, X. (2017). The trends and countermeasure of the public space design of the commercial housing. Journal of Huanan University of Technology (Social Science Edition). 22(4), 112-119.

Temelová, J., \& Slezáková, A. (2014). The changing environment and neighbourhood satisfaction in socialist high-rise panel housing estates: The time-comparative perceptions of elderly residents in Prague. Cities, 37, 82-91.

Tian, Q. (2001). High-rise apartment setting design stressed on environment psychology. Journal of TianJin University, 34(3), 356359.

Tribhuwaneswari, A. B., Darjosanjoto, E. T. S., \& Rachmawati, M. (2016). The spatial consequences of high-Rise building of the public space of Basuki Rahmat corridor, Surabaya. The 1st International Seminar on Science and Technology, Indonesia: Surabaya.
Turkington, R., van Kempen, R., \& Wassenberg, F. (2004). High-rise housing in Europe: Current trends and future prospects. Housing and Urban Policy Studies, 28.

Vasilevska, L. (2013). Towards more userfriendly public open space in low-rise high density housing areas. The 1 st International Conference on Architecture and Urban Design, Tirana. 855-864.

Wang, H. (2008). A brief study on the application of courtyard space in high-rise buildings Housing Science, 12, 39-43.

Wang, H. (2018). Research on public space transformation of old collective housing entrance under the background of open blocks (Master), Zhengzhou University, CNKI.

Wang, N., \& Bay, J. H. (2008). Parametric simulation and pre-parametric design thinking: Guidelines for socio-climatic design of high-rise semi-open spaces. The 21th Conference on Passive and Low Energy Architecture, Eindhoven, Netherlands.

Wei, M. (2015). The research for the design of the public space of bottom aerial on highrise residential building (Master), Zhengzhou University, CNKI.

Weiner, D. J. (1984). A high rise multi-use building for Boston: an investigation into the nature and organization of public space in a tall building. (Master), Massachusetts Institute of Technology.

$\mathrm{Wu}, \mathrm{H}$. (2014). Advancing to the vertical community - strategies for the design of public spaces in the high-rise residential buildings in urban high density areas (Master), Chongqing University, CNKI.

Wu, X., Tao, Y., \& Ni, J. (2004). Discussion on the design of public space and environment of multistory unit house. Journal of Yunnan Agricultural University, 19(6), 751-755.

Xiong, J. (2000). Exploration of communication space in neighborhood-high-rise residence New Architecture, 2, 62-64.

Yin, N. (2013). A study of correlation between Harbin high-rise area open space's architectural layout and microclimate (Master), Harbin Institute of Technology, CNKI.

Yu, H., Sui, X., Bai, G., \& Jiao, M. (2018). Study on the public space design of longrent apartment for youth group - taking port apartment of vanke as an example. Architecture \& Culture, 7, 164-165. 
Yu, S. (2018). Research on optimal design of public space for old high-rise community in urban area based on the needs of youth. (Master), Beijing Jiaotong University, CNKI.

Yuen, B. (2004). Safety and dwelling in Singapore. Cities, 21(1), 19-28.

Zhang, S., \& Sui, N. (2006). Discussion on the relationship between the bottom space of high-rise residential buildings and urban space Urbanism and Architecture, 1, 57-59.

Zhang, W., \& Lawson, G. (2009). Meeting and greeting: Activities in public outdoor spaces outside high-density urban residential communities. Urban Design International, 14(4), 207-214.

Zhang, X. (2007). Survey and analytical study of public space environment of urban residence community--Take the city of Hefei for example. (Master), Hefei University of Technology, CNKI.

Zhang, X., \& Wang, Y. (2012). Call for humanity-reflection on landscape design of urban residence public space. Advanced Materials Research, 450, 1245-1248.

Zhao, Z. (2007). The Research on the significance and constructions of the public space in high-rise building grounding. (Master), Chongqing University, CNKI.

Zhu, Y. (2015). Toward community engagement: Can the built environment help? Grassroots participation and communal space in Chinese urban communities. Habitat International, 46, 44-53. 